\title{
The Basel accords, capital reserves, and agricultural lending
}

\section{Authors: Gary W. Brester and Myles J. Watts}

This is a postprint of an article that originally appeared in Agricultural Finance Review on [date]".

The final version can be found at doi:10.1108/AFR-04-2017-0025

Brester, Gary W. , and Myles J. Watts. "The Basel accords, capital reserves, and agricultural lending." Agricultural Finance Review 79, no. 1 (May 2018): 27-47. DOI:10.1108/ AFR-04-2017-0025. 


\title{
The Basel Accords, Capital Reserves, AND Agricultural Lending
}

\author{
Gary W. Brester and Myles J. Watts
}

\section{Introduction}

The safety and soundness of financial institutions has become a leading worldwide issue because of the recent global financial crisis. Historically, financial crises have occurred approximately every twenty years. The worst financial crisis in the last seventy-five years occurred in 20082009. Financial crises have a variety of causes and are manifest in various ways. The impacts on individuals range from minimal to severe depending on whether or not economic recessions result in high unemployment, loss of equity, or reductions in standards of living. Avoiding future financial crises has become a national and international priority. The primary governmental response has been the introduction of various regulations - the unintended consequences of which could alter the strategic directions of lending institutions. The Basel Accords are an international regulatory response to recent financial crises. Sector customization of the Basel regulations may disproportionally affect concentrated agricultural lenders because spatial production and market price correlations often affect a large number of loans simultaneously. This paper explores the pedagogy of correlated risks within agricultural lending and illustrates how systemic/covariate risks can affect capital reserve requirements of agricultural lenders.

The financial sector is highly concentrated in most countries. For example, in the United States, approximately $43 \%$ of all bank assets are owned by the four largest banks. Bank-related financial problems are often contagious because of the small number of large, financiallyconnected, counterparty relationships. Thus, financial problems in a single, large banking institution can affect other financial institutions (Samitas and Polyzos, 2015). 
The goals of recent banking regulation are to $(\mathrm{GAO})$ :

1. Ensure adequate consumer protections. The profit maximizing goals of financial institutions may encourage the sale of unsuitable financial products and participation in unfair or deceptive practices. Government regulators attempt to address informational asymmetries that consumers and investors may face by providing information about products and services and monitoring business conduct and sales practices.

2. Ensure integrity and the fairness of markets. Because some market participants may be able to manipulate highly concentrated markets to obtain unfair gains in ways that are not easily detectable by other participants, regulators often establish rules and monitor market behavior. Their actions help prevent fraud and market manipulation, limit asset-pricing problems, and encourage efficient market activity.

3. Monitor the financial safety and soundness of institutions. Market opportunities can sometimes lead financial institutions to acquire large risks, which can have significant negative impacts on consumers, investors, and taxpayers. Regulators oversee risktaking activities in an attempt to promote the safety and soundness of financial institutions.

4. Ensure the stability of the overall financial system. Because shocks to a single financial sector or institution can destabilize entire financial systems, regulators attempt to reduce systemic risk in various ways. For example, governments often provide funding (liquidity) to troubled financial institutions to avoid financial system contagion. 
Although banks and other financial institutions have been regulated to varying degrees for centuries, the modern era of bank regulation began with the Basel Agreements, which originated in 1988 with the Basel Committee on Banking Supervision. The original Basel Agreements have since been refined and modified. Although some nations have not fully adopted Basel principles, the Basel Agreements have become the primary guidelines for worldwide bank regulation. Basel I and Basel II provide the current guiding requirements.

Basel III rules are designed to "restore credibility in the calculation of risk-weighted assets and improve the comparability of banks' capital ratios" (Bank for International Settlements, 2017). Basel III reforms seek to improve the robustness and risk sensitivity of standard methods used to calculate credit risk, credit valuation adjustment risk, and operational risk. Basel III recommendations will constrain the use of internal risk based (IRB) models in some cases, and expand it in others. IRB models will be more constrained because limits will be imposed on some variables used to calculate capital requirements. That is, credit valuation risk calculations will be revised to increase sensitivity to risk exposure. In other cases, however, risky asset models will be more customizable as risk weights may be selected to better reflect firmspecific loan-to-value ratios. Most of these changes will be implemented on January 1, 2022.

\section{Regulatory Background}

Current Basel requirements are structured around three pillars: (1) the measurement of credit, market, and operational risk, (2) capital adequacy, and (3) market discipline through enhanced public disclosure or transparency. Pillars 1 and 2 are referred to as the safety and soundness requirements. These requirements are designed to protect "fixed amount creditors" from the failure and insolvency of a financial institution and resulting financial system instability. The 
term "fixed amount" refers to creditor obligations that are independent of market outcomes. Fixed amount creditors include bank depositors and potential insurance beneficiaries. Consequently, the primary regulatory mechanism related to safety and soundness involves capital adequacy.

In the United States, the Sarbanes-Oxley Act of 2002 introduced changes in corporate governance and financial practices regulations. The Dodd-Frank Act of 2010 instituted a multitude of regulations geared towards protecting consumers from various lending practices that presumably contributed to bank failures in 2008. In general, these legislative actions are supposed to improve the financial stability of banking institutions. Both Acts are broad ranging legislation which include a variety of regulatory stipulations. However, each also provides guidance with respect to the maintenance of financial reserve requirements that provide a safety net if large numbers of loan losses occur simultaneously (Walraven and Barry, 2004).

The Basel, Sarbanes-Oxley, and Dodd-Frank regulations are having substantial impacts on capital reserve requirements. The Basel regulations not only address the quantity of required capital reserves, but also the quality of those reserves (Milne, 2001). The regulations emphasize the use of Tier 1 capital, primarily common stock equity and retained earnings, as a means for establishing capital reserve adequacy. Non-accumulating preferred stock is also considered to be Tier 1 capital. The regulations restrict the amount of Tier 2 capital that can be used to meet these requirements. Tier 2 capital is considered to be of lower quality and includes accumulating preferred stock and other capital that is not easily available for absorbing risk.

Basel I and II have been widely criticized as being unduly burdensome (particularly on smaller banks) and blamed for increasing bank sizes. In addition, fixed rules regarding lending practices can often have unintended consequences (Pakravan, 2014). Some argue that increases 
in market concentration have resulted in a less-stable financial system. From a financial perspective, a major shortcoming of Basel I and II is that they provide little consideration of loan portfolio diversification and do not address the value of lower-risk correlations across lending sectors. This may be especially pertinent for smaller (often rural) agricultural lenders who struggle with sectoral diversification (Pederson and Sakaimbo, 2011). In addition, policies that increase the costs of lending may have disparate effects on credit availability among lending sectors such as agriculture (Turvey, 2013). In the United States, some of the Basel III requirements conflict with the Dodd-Frank legislation. Similar internal regulatory conflicts are likely to occur in other countries as well.

Barry (2001) discussed the implication jfo the (then proposed) additions to the Basel accords on capital adequacy in agricultural lending. Primary issues included consideration of the uniqueness of agricultural lending, a general lack of diversification among local agricultural producers, and various approaches to measuring risk. Zech and Pederson (2004) used a value-atrisk model to evaluate the capital adequacy of a Farm Credit System Association using data from 1997-2002. Their analysis indicated that the Association had excess capital reserves relative to minimum requirements. The new Basel Accords, however, were not instituted until later in that decade and may have altered minimum capital requirements. Hence, Ellinger, Hartarska, and Wilson (2005) note that changing regulatory environments necessitate the need for research related to capital adequacy that allows for more flexibility and sophistication if rural lenders were to remain competitive.

In general, Basel III reforms will expand opportunities to customize credit risk models with respect to specific institutions. VaR models that incorporate firm-specific loss correlations in addition to probability-of-default and loss-given-default measures are likely to be increasingly 
used to evaluate capital adequacy. Current regulatory rules allow for only limited flexibility with respect to loss correlations and do not provide sufficient granularity to reflect firm-specific loss correlations. This paper focuses on sector loan loss correlations and diversification in terms of their impacts on capital reserve requirements. The issue is especially pertinent for smaller, agricultural lenders who have limited opportunities to use diversification strategies.

\section{Capital Adequacy}

Capital adequacy refers to the maintenance of specific levels of equity capital by lending institutions as a buffer against adverse outcomes. This buffer allows lenders to meet their obligations to fixed-amount creditors. The justification for requiring a minimum amount of capital reserves is that these funds can be used to meet depositor obligations during times of unusually large loan losses. In addition, the requirements reduce the incentives for lending institutions to increase loan volumes as a means for increasing lending profitability.

Various quantitative approaches can be used to evaluate the safety and soundness of lending institutions (Castro and Garcia, 2014). Lending institutions source capital from various entities and provide capital to borrowers. Of course, such institutions incur risk in the sense that borrowers may not be able to repay principal and accrued interest (i.e., loan default). The ability of a lending institution to repay depositors and bondholders depends upon the amount of equity that is held in reserve and on loan performance. However, if lending institutions did not incur lending risk, then general economic activity would be diminished because of reductions in credit availability. Recent legislation and regulatory authorities have attempted to develop guidelines to improve the financial stability of lending institutions. These actions focus on the maintenance of adequate capital reserves and equity. However, as capital reserves increase, lending profitability 
declines since more equity and/or capital reserves are required for each loaned dollar (Barry, 2001; Rowe, Jovic, and Reeves, 2004).

Several methods can be used to estimate regulatory minimum levels of capital reserves (e.g., risk-weighted asset models, leverage ratios, concentration statistics, value-at-risk methods, etc.) (Gallagher, 2002; Hudson, 2003). Capital adequacy is not only a function of the quantity and quality of equity capital, but also asset composition, riskiness, and relative default correlations within loan portfolios and other financial assets. Consequently, the value-at-risk (VaR) approach is generally considered to be the most statistically-sound method for calculating capital reserve requirements.

The VaR approach accounts for capital quantities, asset quality (e.g., loan loss potential), correlations of loan losses, and loan concentration (i.e., loan diversification). The ability of a lender to meet depositor and bondholder obligations is a random event because of general economic conditions and the potential for widespread loan defaults. The VaR approach calculates capital reserve levels needed to meet these obligations. Most often, the criterion is prespecified at a point where lenders have sufficient reserves to meet their fixed creditor obligations 249 times out of 250 uncertain simulated outcomes (i.e., $99.6 \%$ of the time). We use the VaR approach to illustrate the effect of loan numbers, loan default correlations, and sector concentration on capital reserve requirements.

\section{The Impact of Capital Reserves}

A major goal of privately-owned financial institutions (e.g., banks, insurance companies, etc.) is to maximize return-on-equity within a reasonable risk environment. Hence, we derive a model that relates capital reserve impacts to return-on-equity (Bluhm, Overbeck, and Wagner, 2010; 
Bank for International Settlements, 2017). A simplified expression for total return-to-equity for loan portfolios is given by:

$$
R T E=i L-z L-c F
$$

where $R T E$ is the to return-to-equity; $i$ the interest rate charged on loans; $L$ the loan volume; $z$ the operating and loan default costs per dollar of loan value; $c$ the cost (per dollar) of funds obtained by a lender (e.g. demand deposits, bond sales, etc.); and $F$ the amount of funds obtained by a lender

Note that:

$$
R T E=(R O E)(E)
$$

where $R O E$ is the return per dollar of equity and $E$ is total equity.

Therefore,

$$
(R O E)(E)=i L-z L-c F .
$$

Scaling this relationship to a per-dollar-of-loan-volume basis is accomplished by dividing both sides of the equation by $L$ :

$$
(R O E)\left(\frac{E}{L}\right)=i-z-c\left(\frac{F}{L}\right) .
$$

Loanable funds are obtained from a combination of equity and acquired funds. Consequently,

$$
L=E+F,
$$

which can be rewritten as

$$
1=\left(\frac{E}{L}\right)+\left(\frac{F}{L}\right) .
$$

After letting $\left(\frac{E}{L}\right)=w$, then $\left(\frac{F}{L}\right)=(1-w)$, and

$$
(R O E)(w)=i-z-c(1-w)
$$




$$
R O E=\frac{i-z-c(1-w)}{w}
$$

For illustration purposes, assume that a lender chooses a strategy of retaining the minimum required amount of capital reserves in an effort to maximize return-on-equity. ${ }^{1}$ Thus, $w$ is also a measure of required capital reserves per dollar of loan volume.

To illustrate the relationship between capital reserves and return-on-equity, assume that $i=0.06$ which is the U.S. 20-year average interest rate of non-real estate loans, $z=0.015$ which is a representative value for default costs, and $c=0.035 .^{2}$ Then,

$$
R O E=\frac{0.06-0.015-0.035(1-w)}{w} .
$$

Figure 1 shows that at an unrealistically low amount of capital reserves per loan (say, \$0.02), return-on-equity is a lofty $53.5 \%$ because of the related high level of bank default risk. However, even moderate increases in capital reserves substantially reduce return-on-equity. For example, return-on-equity declines to $23.5 \%$ if capital reserves per loan increase to $\$ 0.05$, and falls to $8.5 \%$ if capital reserves per loan increase to $\$ 0.20$.

For purposes of context, the historical return-on-equity in banking (and other businesses that incur similar risk) ranges between 10-15\% (Federal Reserve Bank of St. Louis, 2018). In addition, a capital reserve rate of $8 \%$ for Tier 1 capital is the minimum value allowed by Basel regulations, and is often used as a benchmark for capital reserves in the absence of Internal Risk Based (IRB) modeling (Bank for International Settlements, 2017). The Tier 1 capital ratios in

${ }^{1}$ In some cases, equity and capital reserves (Tier 1 capital) may be identical. For example, they are equivalent if equity consists of only certain categories such as common stock, retained earnings (profits), non-accumulating preferred stock, and mezzanine capital. However, if the equity component of a balance sheet also includes an item such as accumulating preferred stock, then that component of equity is not considered Tier I capital.

2 The current long term Treasury Bill rate is 3.1\%. Cost of funds for the Farm Credit System is slightly higher than the Treasury Bill rate. Hence, we use 3.5\% for illustrative purposes. 
2017 for the five largest U.S. banks ranged between 11\% and 17.5\% (Clarus Financial Technology, 2018). Clearly, incentives exist to minimize capital reserve requirements in an effort to increase return-on-equity.

Figure 1. Relationship Between Return-to-Equity and Capital Reserves.

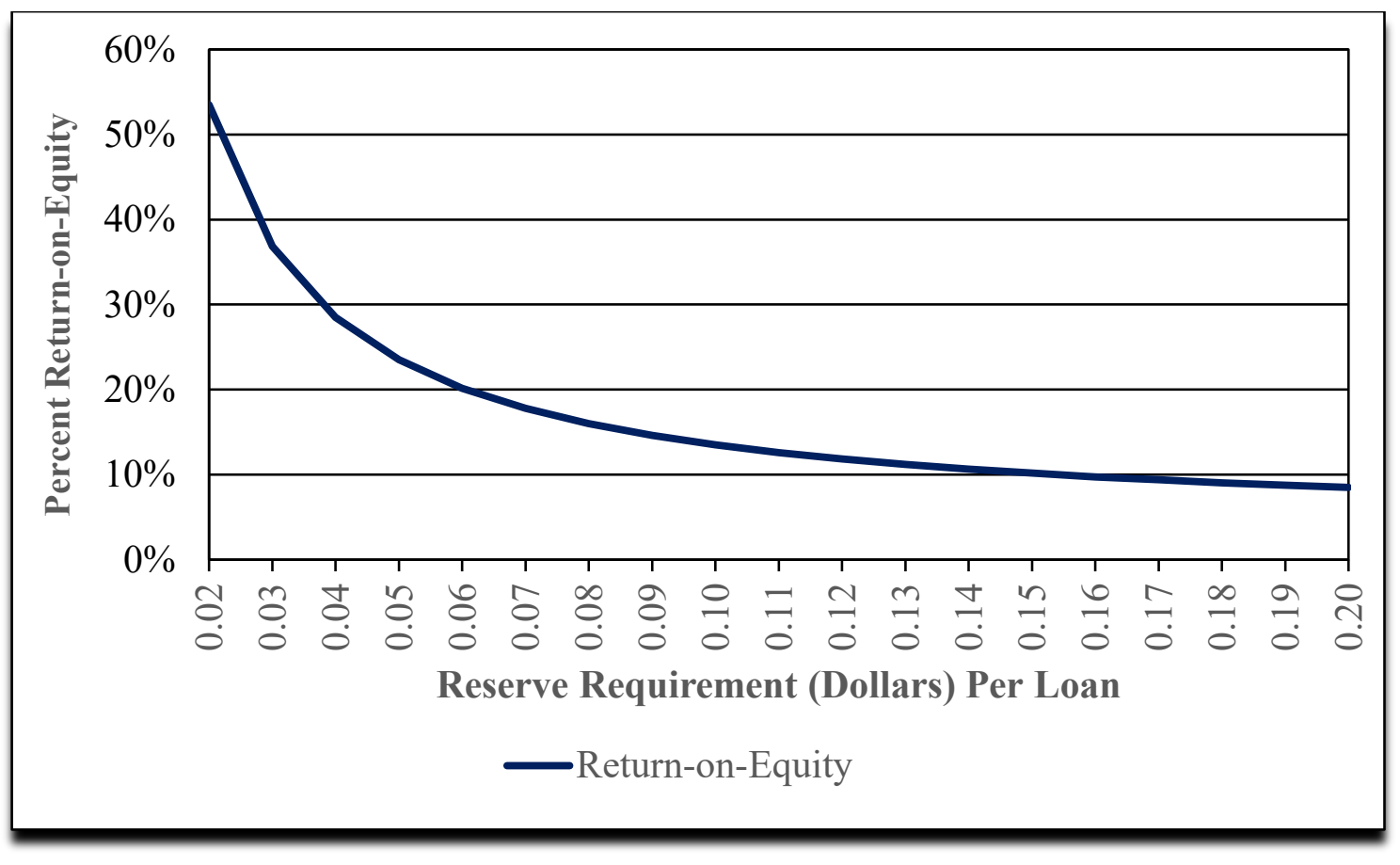

Although increases in capital reserve requirements reduce credit availability, such increases also have a socially-beneficial outcome in that the risk of lender insolvency is reduced. From a public policy perspective, lender insolvency affects others beyond the stockholders of lending institutions. This wider impact provides a rationale for financial institution regulations.

\section{Value-at-Risk Approach}

The value-at-risk $(\mathrm{VaR})$ approach considers the probability of loan defaults, correlations among loan losses, and diversification impacts (Bluhm, Overbeck, and Wagner, 2010; Artzner, et al., 
1999). We first show VaR calculations for a single loan before moving to more complicated multiple loan examples.

\section{A Single Loan VaR Example}

For simplicity, consider the capital reserve requirement for a lender who has issued a single annual loan that has a year-end principal and interest payoff of $\$ 0.50$. Further, assume the borrower's available funds for the loan payoff is $x$. Of course, $x$ contains an element of risk in that future available funds needed to repay the loan are not known with certainty. Assume that fund availability follows a normal distribution with a mean $(\mu)$ of $\$ 1.00$ and a standard deviation $(\sigma)$ equal to 0.25 . Then,

$$
\operatorname{prob}(x<0.50)=0.0227 .
$$

Hence, the probability of loan default is $2.27 \%$.

The VaR approach calculates the amount of capital reserves that would be required for a lender to offset a default on this loan $99.6 \%$ of the time. The calculation uses the inverse of the probability (99.6\%) of loan default and the normal cumulative distribution to obtain:

$$
z_{0.996}=I N V(\text { prob }=0.996)=2.65 .
$$

Thus,

$$
\operatorname{VaR}_{0.996}=\mu-z_{0.996} \sigma=\$ 1.00-2.65(0.25)=\$ 0.3375 .
$$

The required capital reserves for this simplified example would be:

$$
\text { Capital Reserves }=\$ 0.50-\$ 0.3375=\$ 0.1625 \text {. }
$$

To summarize, assume that a lender has promised to repay a direct depositor $\$ 0.50$ at the end of the year. The lender has used these funds to provide a loan to a borrower, and expects the borrower to return $\$ 0.50$ of principal and interest at the end of the same year. The borrower 
expects, on average, to have $\$ 1.00$ at the end of the year to make that payment and for other uses. However, the borrower's available funds are a random variable because of personal, production, and market risks. If the borrower's available funds follow a normal distribution with a mean of $\$ 1.00$ and a standard deviation of 0.25 , then the lender would need to maintain $\$ 0.1625$ of capital reserves for this $\$ 0.50$ loan payoff to meet its obligations to the direct depositor $99.6 \%$ of the time. This relatively sizable reserve requirement occurs because only a single loan is being issued. Without loss of generality, this very small loan can be scaled to represent commercial loan amounts.

Note that this example represents capital reserve requirements on a per loan basis. If one assumes a $6 \%$ interest rate and a $\$ 0.50$ loan payoff, then the capital reserve requirement can be converted to a per dollar-of-loan basis by multiplying $\$ 0.1625$ by 2.12 (i.e., $1 /[0.50 / 1.06]$ where $0.50 / 1.06=0.4717$ is the loan amount) to yield $\$ 0.3445$.

\section{A Multiple Loan VaR Example}

Consider the case of a lender who makes two loans rather than a single loan. Assume that the mean and standard deviation of the borrowers' available funds for each loan are identical, but not perfectly correlated. If two loan loss distributions are perfectly correlated, then both loans default at the same time with identical losses given default. If borrower available funds for the two loans were perfectly correlated, then the capital reserve requirements per loan would be identical to the single loan example above. However, even if borrower available funds for the two loans are positively (but not perfectly) correlated, capital reserves requirements per loan will be lower. 


\section{Simulation Procedures for Calculating Capital Reserve Requirements}

Unlike the single loan case, there is no closed form mathematical solution to this two (or more) loan case if loan payments are less than perfectly correlated. It is possible, however, to use simulation methods to obtain a solution. The method for obtaining the solution, however, is cumbersome as the number of loans becomes moderately large. Consequently, we use an adjusted Beta distribution approximation to calculate capital reserve requirements. ${ }^{3}$

The following notation is used to calculate the capital reserve requirements for multiple homogeneous loans:

$$
\begin{aligned}
& \rho=\text { the correlation of loan payments (which is assumed to be identical across every } \\
& \text { loan combination) } \\
& P=\text { loan payoff for each loan which includes both principal and interest } \\
& x=\text { funds available for loan payoffs } \\
& \mu=\text { mean of } x \\
& \sigma^{2}=\text { variance of } x \\
& f[\bullet]=\text { normal probability density function } \\
& F[\bullet]=\text { normal cumulative density function } \text {. }
\end{aligned}
$$

The expected loss and variance of losses for an individual loan must first be calculated. Let $L$ represent loan losses such that:

$$
\begin{aligned}
& L=P-x \text { if } x<P, \text { and } \\
& L=0 \text { if } x \geq P .
\end{aligned}
$$

Therefore, the expected loss is:

${ }^{3}$ The Beta distribution is commonly used for the risk modeling of loan loss distributions because it can approximate a wide variety of other distributions depending upon its parameter values (Bluhm, Overbeck, and Wagner, 2010). Nonetheless, other distributions including the Normal and Gamma are also sometimes used. 


$$
\begin{aligned}
E L & =\int_{-\infty}^{\infty} L f[x] d x \\
& =\int_{-\infty}^{P}(P-x) f(x) d x \\
& =\sigma^{2} f[P]+(P-\mu) F[P] .
\end{aligned}
$$

The variance of any single loan loss is:

$$
\begin{aligned}
V L & =\int_{P}^{\infty}(0-E L)^{2} f[x] d x+\int_{-\infty}^{P}(L-E L)^{2} f[x] d x \\
& =\sigma^{2} F[P]+(P-\mu) E L-E L^{2} .
\end{aligned}
$$

The derivations for the expected loss and variance of loss formulas are presented in Appendix A.

Given that we know the expected loss $E L$ (equation 18) and the variance of losses $V L$ (equation 20) for any single loan, we use the following process to estimate the capital reserves required for a large number of loans:

1. Calculate $E L$ and $V L$ (Appendix B).

2. The portfolio loan loss is given by $E L_{P}=E L$. For a large number of loans with each pair correlated by $\rho$, the variance of the portfolio loan losses is given by $V L_{P}=\rho V L$. Thus, the variance of the loan portfolio is equal to the correlation coefficient multiplied by the variance of the individual loan loss.

To illustrate, consider three loans $x_{1}, x_{2}$, and $x_{3}$. The variance of the portfolio of these three loans is given by

$$
\begin{aligned}
V L_{n=3}= & V L_{1}+V L_{2}+V L_{3}+2 \rho_{12} \sqrt{V L_{1}} \sqrt{V L_{2}}+2 \rho_{13} \sqrt{V L_{1}} \sqrt{V L_{3}} \\
& +2 \rho_{23} \sqrt{V L_{2}} \sqrt{V L_{3}} .
\end{aligned}
$$

After rescaling so each loan represents one-third of the portfolio, 


$$
\begin{aligned}
V L_{n=3}=\frac{V L_{1}}{3^{2}} & +\frac{V L_{2}}{3^{2}}+\frac{V L_{3}}{3^{2}}+2 \rho_{12}\left(\frac{\sqrt{V L_{1}}}{3}\right)\left(\frac{\sqrt{V L_{2}}}{3}\right)+2 \rho_{13}\left(\frac{\sqrt{V L_{1}}}{3}\right)\left(\frac{\sqrt{V L_{3}}}{3}\right) \\
& +2 \rho_{23}\left(\frac{\sqrt{V L_{2}}}{3}\right)\left(\frac{\sqrt{V L_{3}}}{3}\right) .
\end{aligned}
$$

Assume that $V L=V L_{1}=V L_{2}=V L_{3}$ and $\rho=\rho_{12}=\rho_{13}=\rho_{23}$, then

$$
\begin{aligned}
V L_{n=3} & =3\left(\frac{V L}{3^{2}}\right)+6 \rho\left(\frac{V L}{3^{2}}\right) \\
& =\frac{1}{3} V L+\frac{2}{3} \rho V L .
\end{aligned}
$$

Consequently, for any $n$ loans with a variance of $V L$ and correlation of $\rho$, the general equation for the variance of the portfolio is given by:

$$
\begin{aligned}
V L & =n\left(\frac{V L}{n^{2}}\right)+(n-1)(n) \rho\left(\frac{V L}{n^{2}}\right) \\
& =\frac{V L}{n}+\left(\frac{n-1}{n}\right) \rho V L
\end{aligned}
$$

and the $\lim _{n \rightarrow \infty} V L_{n}=\rho V L=V L_{P}$. Note that if $n$ is large and there is no correlation among loans (i.e., $\rho=0$ ), then zero capital reserves are necessary. However, as is the case in any lending situation, $n$ will not be equal to infinity and loans will be correlated such that $\rho \neq 0$. It can be shown that $\rho$ cannot be negative which implies $V L_{P} \geq 0$. Note that the portfolio variance is highly sensitive to the size of $\rho$ if the number of loans is large.

3. The $\operatorname{Beta}(\alpha, \beta)$ distribution with a range $[0,1]$ is used to calculate required capital reserves. The parameters $\alpha$ and $\beta$ are calculated for $E L_{n}$ and $V L_{n}$ using the procedure described in Appendix C. 


\section{Capital Adequacy, VaR, Loan Numbers, and Loan Correlations}

The following capital adequacy calculations are developed assuming that every loan within a single sector (say, agriculture) has an identical payoff (\$0.50) and an identical loan loss distribution $\rho_{i j}=\rho$. This simplifying assumption is used to isolate the impacts of loan numbers and within-sector loan loss correlations. Again, the mean of borrower available funds is assumed to be $\$ 1.00$ with a standard deviation of 0.25 . Of course, funds available for loan payoffs are a random variable. Hence, fund availability may be either higher or lower than the $\$ 0.50$ loan payoff - which creates a risk of loan default. Although the distributions of loan losses are assumed to be identical for each loan, it is unlikely that the correlation between loan losses is equal to 1.0. That is, some borrowers may make their usual interest and principal payments, while others might default. Consequently, as the number of loans within a single sector increases, the chances that a large number of loan losses would exceed a lender's capital reserves within any single year declines. If loan losses are not perfectly correlated, increases in loan numbers (even with identically-sized loans with equal probabilities of default) will reduce lender capital reserve requirements. Note that if a loan "portfolio" consists of a single loan, the probability of "all" loans defaulting is identical to the probability of default of the single loan.

Table 1 presents the capital reserve requirements for various loan loss correlations across loans within a single sector and for an increasing number of loans in that sector. For a single loan, $\$ 0.163$ of capital reserves per loan (recall that each loan has a $\$ 0.50$ payoff) are required to ensure that a lender has a $99.6 \%$ probability of meeting depositor or bond commitments. Recall that across-loan default correlations are irrelevant if a "portfolio" consists of a single loan. 
Table 1. Capital Requirements Per Loan by Loan Numbers and Loan Loss Correlations

\begin{tabular}{cccccc} 
& \multicolumn{5}{c}{ Across-Loan Loss Correlations } \\
Number & & & & \\
Of Loans & 0.20 & 0.40 & 0.60 & 0.80 & 1.00 \\
\hline 1 & 0.1630 & 0.1630 & 0.1630 & 0.1630 & 0.1630 \\
2 & 0.1279 & 0.1365 & 0.1440 & 0.1506 & 0.1630 \\
3 & 0.1010 & 0.1236 & 0.1348 & 0.1442 & 0.1630 \\
4 & 0.0993 & 0.1160 & 0.1294 & 0.1404 & 0.1630 \\
5 & 0.0922 & 0.1111 & 0.1260 & 0.1379 & 0.1630 \\
6 & 0.0874 & 0.1079 & 0.1237 & 0.1363 & 0.1630 \\
7 & 0.0839 & 0.1056 & 0.1221 & 0.1352 & 0.1630 \\
8 & 0.0813 & 0.1039 & 0.1210 & 0.1344 & 0.1630 \\
9 & 0.0793 & 0.1026 & 0.1202 & 0.1340 & 0.1630 \\
10 & 0.0778 & 0.1017 & 0.1196 & 0.1336 & 0.1630 \\
11 & 0.0764 & 0.1009 & 0.1191 & 0.1333 & 0.1630 \\
12 & 0.0754 & 0.1003 & 0.1188 & 0.1331 & 0.1630 \\
13 & 0.0745 & 0.0998 & 0.1185 & 0.1330 & 0.1630 \\
14 & 0.0737 & 0.0994 & 0.1183 & 0.1328 & 0.1630 \\
15 & 0.0731 & 0.0990 & 0.1181 & 0.1327 & 0.1630 \\
$\bullet$ & $\bullet$ & $\bullet$ & $\bullet$ & $\bullet$ & $\bullet$ \\
Infinity & 0.0636 & 0.0941 & 0.1156 & 0.1318 & 0.1630 \\
\hline
\end{tabular}

It is often the case that agricultural loan defaults among borrowers are positively correlated. Even so, if the number of loans within this portfolio is doubled (i.e., the number of loans now equals 2 and both loans are of the same size) and the loan loss correlation among the two is 0.60 , then capital reserve requirements are reduced to $\$ 0.144$ per loan. Note that lower capital reserves are required as the correlation among loan losses declines. For example, if the loan loss correlation among these two loans is 0.20 , then only $\$ 0.127$ of capital reserves per loan are needed. On the other hand, a higher correlation (say 0.80 ) would require a capital reserve of $\$ 0.150$ per loan. If the loan default correlation among all loans was equal to 1.0 (i.e., perfectly correlated), then the reserve requirements would be $\$ 0.163$ regardless of the number of loans considered. 
Across less-than perfectly correlated loan losses, capital reserve requirements decline as the numbers of loans increase. The decline is more rapid for lower loan loss correlations relative to higher correlations. However, declines in capital reserve requirements slow markedly as the loan portfolio approaches 15 loans. Hence, only small differences exist between the capital reserve requirements for 15 loans versus a very large number of loans in each correlation category. For example, if the loan loss correlation is 0.60 , then $\$ 0.118$ of capital reserves per loan is required for 15 loans, while $\$ 0.115$ of reserves per loan is required for an infinite number of loans.

The relationships between capital reserve requirements, loan loss correlations, and loan numbers are also presented in Figure 2. Reserve requirements decline relatively quickly as loan numbers increase. Given that across-loan loss correlations in agriculture are generally 0.40 or greater, capital reserve requirements do not substantially change as the number of loans exceeds 15.

Figure 2. Capital Reserve Requirements, Loan Numbers, and Loan Loss Correlations

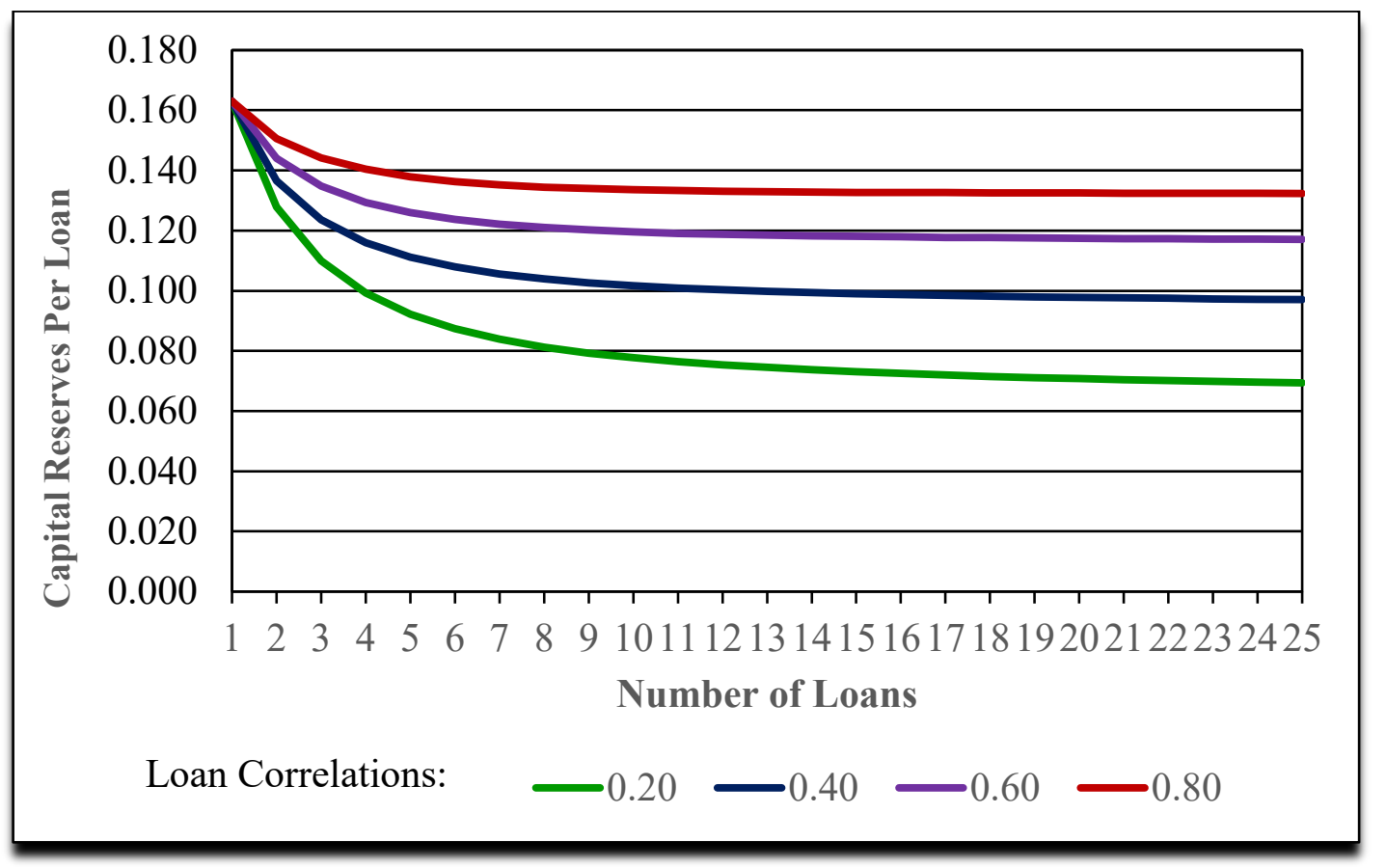




\section{Capital Adequacy, VaR, and Sector Diversification}

The above example shows that capital reserve requirements decline as the number of loans (even identical loans within a given sector) increase if loan losses are not perfectly correlated. Similarly, increased diversification across loan sectors can also reduce capital reserve requirements if across-sector loan losses are not perfectly correlated.

To illustrate the impact of sector diversification, we expand the above analysis to include a second (and later, more) sector. Assume a loan portfolio consists of a large number of loans in one sector (say, agriculture) and a large number of loans in a second sector (say, commercial real estate). We assume that within each sector, loan loss correlations equal 0.60. Also, we continue with the assumption that all loans are identical in terms of size and further assume that the same number of loans occur within each lending sector. Consequently, if two sectors are being considered, each sector is assumed to represent one-half of the loan portfolio. This allows us to isolate across-sector diversification effects on capital reserve requirements as the number of loan sectors increase.

Table 2 shows that if only one sector is considered, capital reserve requirements $(\$ 0.115$ per loan) are the same as shown in Table 1 for the case of a large number of loans and a 0.60 within-sector loan loss correlation. Clearly, across-sector loan loss correlations are irrelevant if only a single sector is considered. However, for two sectors with an across-sector loan loss correlation of 0.50 , capital reserve requirements decline to $\$ 0.092$ per loan. Capital reserve requirements are lower $(\$ 0.086)$ if the across-sector loan loss correlation is smaller $(0.25)$, and higher $(\$ 0.098)$ for an across-sector loan loss correlation of 0.75 . 


\begin{tabular}{ccccc} 
& \multicolumn{4}{c}{ Across-Sector Loan Loss Correlations } \\
\cline { 2 - 5 } Number & & & & \\
Of Sectors & 0.25 & 0.50 & 0.75 & 1.00 \\
\hline 1 & 0.1156 & 0.1156 & 0.1156 & 0.1156 \\
2 & 0.0869 & 0.0929 & 0.0984 & 0.1156 \\
3 & 0.0741 & 0.0834 & 0.0916 & 0.1156 \\
4 & 0.0668 & 0.0781 & 0.0879 & 0.1156 \\
5 & 0.0620 & 0.0748 & 0.0856 & 0.1156 \\
6 & 0.0587 & 0.0725 & 0.0841 & 0.1156 \\
7 & 0.0562 & 0.0708 & 0.0829 & 0.1156 \\
8 & 0.0543 & 0.0695 & 0.0821 & 0.1156 \\
9 & 0.0527 & 0.0684 & 0.0814 & 0.1156 \\
10 & 0.0515 & 0.0676 & 0.0809 & 0.1156 \\
$\mathbf{:}$ & $\mathbf{:}$ & $\mathbf{:}$ & $\mathbf{:}$ & $\vdots$ \\
Infinity & 0.0389 & 0.0597 & 0.0757 & 0.1156 \\
\hline
\end{tabular}

If across-sector loan loss correlations are perfectly correlated (i.e., a 1.0 correlation coefficient), then increasing the number of sectors (increasing diversification or reducing concentration) has no impact on capital reserve requirements (i.e., the reserve requirement is always $\$ 0.115$ ). For less-than-perfect across-sector loan loss correlations, however, increasing the number of sectors reduces reserve requirements. Note that reductions in capital reserve requirements become relatively small as the number of sectors approaches 10 . For example, if the loan loss correlation across sectors is 0.50 , then the capital reserve requirement for 3 sectors would be $\$ 0.083$, and for 10 sectors would be $\$ 0.067$. For a large number of sectors, the reserve requirements would be $\$ 0.059$.

It would at first appear that lending to 10 different sectors would be unrealistic for many lenders. Substantial expertise is needed and additional costs are incurred whenever additional lending sectors are added to a loan portfolio. However, even if a lender focuses on, say, 5 sectors in a region, a similar focus in a different region would increase the number of lending sectors to 
10. The recent increase in loan activity by large lenders across sectors, regions, and countries can be partially traced to regulatory demands on capital adequacy.

Figure 3 shows the impact of increasing the number of lending sectors (i.e., decreasing sector concentration) and across-sector loan loss correlations on capital reserve requirements. Note that the largest reductions in capital reserve requirements occur as the number of sectors increases to about 5 . Reductions in capital reserve requirements decline more slowly as the number of sectors exceed 10 . With the exception of a single sector, lower capital reserves are required as across-sector loan loss correlations decline.

Figure 3. Capital Reserve Requirements, Number of Sectors, and Across-Sector Loss Correlations

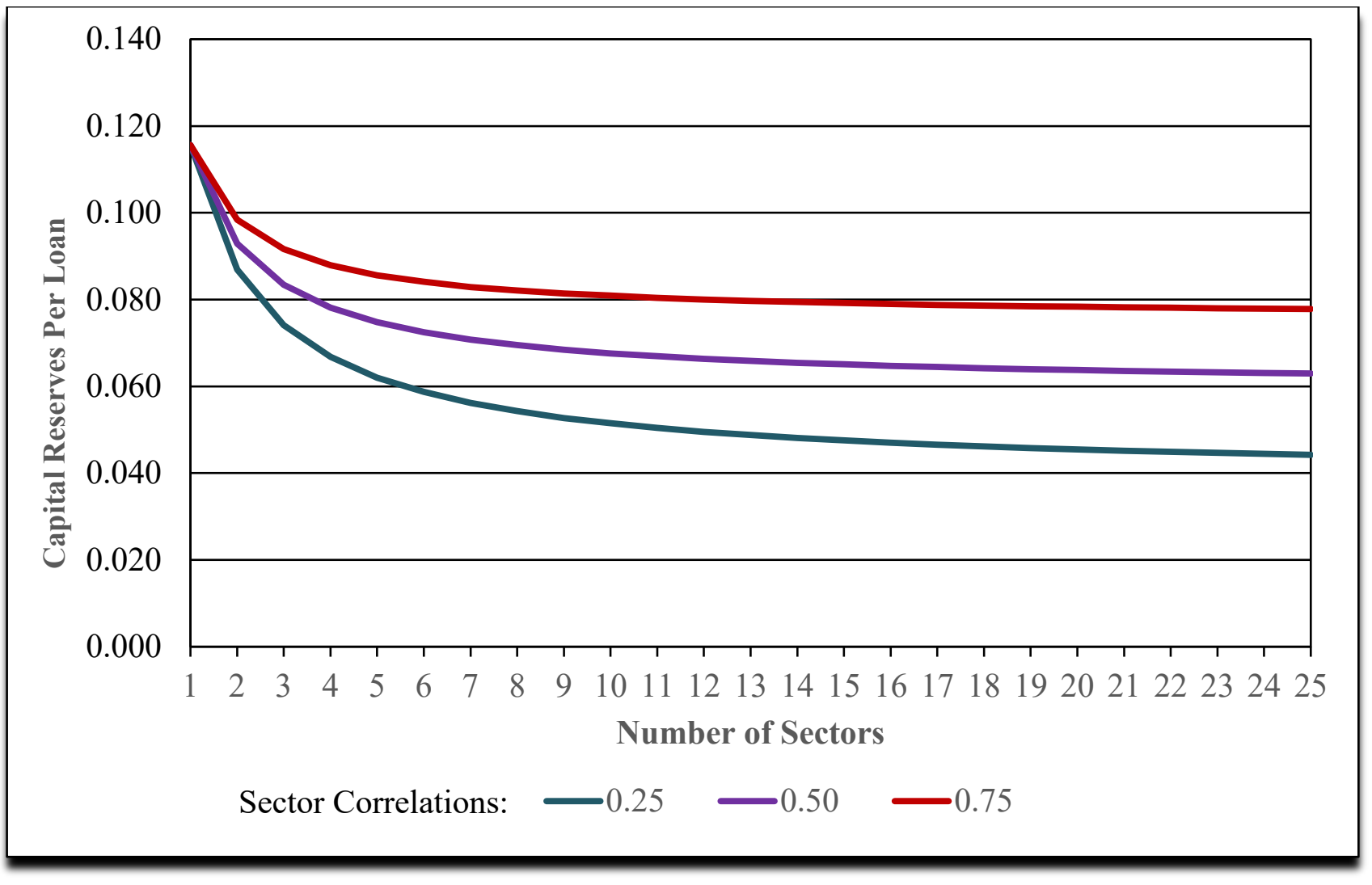




\section{An Empirical Example}

The development of a complete $\mathrm{VaR}$ model requires estimates of revenue correlations among sectors. However, a realistic model would also need to include such variables as collateral values, foreclosure costs, and numerous other factors. Such a modeling procedure is beyond the scope and space constraints of this paper. We can, however, provide some insights into the correlations among loan sectors (and by extension, impacts on capital reserve requirements) by considering a simplified example of revenue correlations across different agricultural production scenarios and a non-agricultural sector. ${ }^{4}$ The analysis requires farm-level, time series data on revenues so that correlations within a lending portfolio can be calculated. These data are not generally available to researchers. Hence, Appendix D presents a method that allows unavailable farm-level data to be approximated using available county-level data. We consider two farm types - a wheat farm in Choteau County, Montana, and a corn farm in Cass County, Nebraska. In addition, we consider oil production as a third sector as it is unrelated to agricultural production. Nonetheless, it is certainly possible that some correlation exists between farm output prices and oil prices.

We begin with the simplest case and calculate revenue correlations between two wheat farms in Choteau County, Montana, and assume that each farmer in the county receives identical wheat prices. We use NASS (2017) county-level data for wheat prices and yields from 19502016. Wheat prices were first deflated using the GDP implicit price deflator. The resulting real price series was then detrended by regressing price onto a linear time trend and a one-period lag on real prices. Wheat yields were detrended using a linear time trend only. The county wheat

${ }^{4}$ It is common to use asset value correlations as a proxy for loan loss correlations (Bluhm, Overbeck, and Wagner, 2010). In our example, asset values are represented by crop values. Therefore, we use crop value revenue correlations as proxies for loan loss correlations. 
price coefficient of variation was calculated by dividing the standard error of the detrended wheat price regression by the predicted (i.e., expected) 2017 price. The county yield coefficient of variation was calculated in a similar manner. The farm yield deviation coefficient of variation was assumed to be equal to the county yield coefficient of variation which is consistent with the county yield variance being approximately equal to the farm yield deviation variance (Watts, 2009). The price correlation between the two wheat farms is equal to 1.0 because of the assumption that all farmers receive the same wheat price within a county. The county yield correlation is also equal to 1.0 because, by definition, all farmers within a county have the same county average yield. The estimated parameters are presented in the second column of table 3 . The values are then used to populate equation (D.24) to obtain an estimate of the revenue correlation coefficient among wheat farms which equals 0.87 .

\section{Table 3. Values Used to Calculate Revenue Correlation Coefficients across Sectors}

\begin{tabular}{cccc} 
& \multicolumn{3}{c}{ Sectors } \\
\cline { 2 - 4 } Parameters & Wheat/Wheat & Wheat/Corn & Wheat/Oil \\
\hline$\psi_{W}$ & 0.44 & 0.44 & 0.44 \\
$\psi_{B}$ & 0.44 & 0.30 & 0.33 \\
$\psi_{Y}$ & 0.17 & 0.17 & 0.17 \\
$\psi_{V}$ & 0.17 & 0.14 & 0.00 \\
$r_{W, B}$ & 1.0 & 0.70 & 0.27 \\
$r_{Y, V}$ & 1.0 & -0.02 & 0.00 \\
$\rho$ & 0.87 & 0.51 & 0.23 \\
\hline
\end{tabular}

The second case considers revenue correlations between a wheat farm in Choteau County, Montana and a corn farm in Cass County, Nebraska. Coefficients of variation for real corn prices and yields were calculated similarly to those for wheat. To calculate the correlations between corn and wheat prices and county corn and wheat yields, the annual residuals from the 
detrending regressions were added to their predicted 2017 values. The resulting time series was used to calculate the correlations between corn and wheat prices and between corn and wheat yields. It is assumed that at the farm and county levels, prices and yields for each commodity are independent. The estimated parameter coefficients are presented in the third column of table 3 . Using these in equation (D.24) results in a revenue correlation coefficient between wheat farms in Choteau County, Montana and corn farms in Cass County, Nebraska of 0.51. This illustrates the importance of spatial and commodity diversification in terms of reducing revenue correlations. As shown in Figure 3, lower revenue correlations across loan sectors reduces capital reserve requirements.

Further reductions in capital reserve requirements through the use of diversification can be illustrated using a non-agricultural loan sector. Thus, the third case presents the revenue correlation between a wheat farm in Choteau County, Montana and an oil producing company. In this case, annual national crude oil price data from 1950-2016 are used (InflationData.com). After deflating the data, the resulting real price series did not exhibit a trend. Real oil prices were used to calculate the oil price coefficient of variation and the correlation coefficient between wheat and oil prices. We assume no variation in oil production yields. So, the oil yield coefficient of variation is 0 . The values used to populate equation (D.24) are presented in the fourth column of table 3 and results in a revenue correlation coefficient between wheat farms and oil production of 0.23 .

In summary, Figure 3 showed the substantial influence of correlations on required capital levels using a VaR approach. The above estimates of across-sector revenue correlations using actual county-level data provides strong evidence that such correlations vary substantially 
depending on loan portfolio composition. Consequently, incorporating a wide range of sectors in a loan portfolio can substantially reduce capital reserve requirements.

\section{Summary}

Capital reserve requirements have become an important component of lending regulations and are designed to improve the safety and soundness of the financial sector. That is, larger capital reserves reduce the probability that multiple, simultaneous loan defaults will cause a lending institution to become insolvent. On the other hand, maintaining larger capital reserves reduces the profitability of lending institutions and may reduce economic activity.

Although various methods exist for determining capital reserve requirements, the valueat-risk (VaR) approach is the most statistically-sound because it not only considers the quantity and quality of loans and asset portfolios, but also the correlation of loan losses within and across lending sectors.

This paper illustrates that capital reserve requirements decline as the number of loans increase and as additional lending sectors are added to loan portfolios. In all cases, lower withinsector and across-sector loan loss correlations reduce capital reserve requirements. The results also indicate that capital reserve requirements are not substantially reduced after loan numbers exceed a relatively low number (10-15). Hence, smaller lending institutions can compete with larger institutions with respect to loan numbers.

Sector diversification reduces capital reserve requirements if across-sector loan correlations are less-than-perfectly correlated. In addition, as across-sector loan correlations become smaller, capital reserve requirements are further reduced. Although sector diversification lowers capital reserve requirements, our results have not considered increased lending costs associated with expanding loan portfolios across sectors, regions, and countries. These actions 
often require additional technical expertise and other costs, which can be substantial particularly for smaller lending institutions.

Agricultural loan losses have relatively low correlations with other sectors. Given the results of this paper, non-traditional agricultural lenders are likely to increase their loan volumes and seek additional loan sector diversification. Hence, traditional agricultural lenders can expect increased competition for agricultural loans as other lenders seek additional sector diversification as a means to reduce capital reserve requirements. 


\section{References}

Artzner, P., Delbaen, F., Eber, J. and Heath, D. (1999), "Coherent measures of risk," Mathematical Finance, Vol. 9, No. 3, pp. 203-228.

Bank for International Settlements. (2017). "Basel Committee on Banking Supervision: High Level Summary of Basel III Reforms". Available at www.bis.org, ISBN 978-92-9259-118-2 (online), (accessed April, 17, 2018).

Barry, P. (2001), "Modern capital management by financial institutions: Implication for agricultural lenders", Agricultural Finance Review, Vol. 61, No. 2, pp. 103-122.

Bluhm, C., Overbeck, L. and Wagner, C. (2010), Introduction to Credit and Risk Modeling, Second Ed., Chapman \& Hall, London, UK.

Castro, C. and Garcia, K. (2014), "Default risk in agricultural lending, the effects of commodity price volatility and climate", Agricultural Finance Review, Vol. 74, No. 4, pp. 501-521.

Clarus Financial Technology. (2018). www.clarusft.com. Accessed April 17, 2018.

Ellinger, P, Hartarska, V. and Wilson, C. (2005), "Structure, performance, and risk management of financial institutions", Agricultural Finance Review, Vol. 65, No. 2, pp. 183-200.

Federal Reserve Bank of St Louis. (2018). www.fred.stlouisfed.org. Accessed April 17, 2018.

Gallagher, R.L. (2002), "Modeling agricultural loan portfolio risk in a stochastic environment", Agricultural Finance Review, Vol. 62, No. 1, pp. 25-39.

Hudson, R. (2003), “Dealing with Basel II: Basel II- the end of risk management?", Balance Sheet, Vol. 11, No. 4, pp. 32-35.

InflationData.com. https://inflationdata.com/Inflation/Inflation_Rate/ Historical_Oil_Prices_Table.asp. Accessed December, 2017.

Milne, A. (2001), "Minimum capital requirements and the design of the new Basel Accord: A constructive critique", Journal of Financial Regulation and Compliance, Vol. 9, No. 4, pp. 312326.

National Agricultural Statistics Service. https://www.nass.usda.gov/. Accessed December, 2017.

Pakraven, K. (2014), "Bank capital: the case against Basel”, Journal of Financial Regulation and Compliance", Vol. 22, No. 3, pp. 208-218.

Pederson, G. and Sakaimbo, N. (2011), "Default and loss given default in agriculture", Agricultural Finance Review, Vol. 71, No. 2, pp. 148-161. 
Rowe, D., Jovic, D., and Reeves, R. (2004), "The continuing saga - Basel II developments; bank capital management in the light of Basel II - how to manage capital in financial institutions", Balance Sheet, Vol. 12, No. 3, pp. 15-21.

Samitas, A. and Polyzos, S. (2015), “To Basel or not to Basel? Banking crises and contagion”, Journal of Financial Regulation and Compliance, Vol. 23, No. 3, pp. 298-318.

Turvey, C. (2013), "Policy rationing in rural credit markets", Agricultural Finance Review, Vol. 73, No. 2, pp. 209-232.

United States Government Accountability Office, (2009), "Financial Regulation: A Framework for Crafting and Assessing Proposals to Modernize the Outdated U.S. Financial Regulator System." Report to Congressional Addressees. GAO-09-216. Washington, DC. Available at: http://www.gao.gov/new.items/d09216.pdf (accessed 17 January 2017).

Walraven, N. and Barry, P. (2004), "Bank risk ratings and the pricing of agricultural loans", Agricultural Finance Review, Vol. 64, No. 2, pp. 107-118.

Watts, M. The Efficacy of Proxy Index Insurance. Presentation to the Gates Foundation, Seattle, WA. September 2009.

Zech, L., and Pederson, G. (2004), “Application of credit risk models to agricultural lending”, Agricultural Finance Review, Vol. 64, No. 2, pp. 91-106. 


\section{Appendix A}

\section{Expected Loss and Variance Proofs}

The distribution of losses is a truncated distribution in which the values may either be zero or some positive value. Since the funds available (denoted by $x$ ) are normally distributed with a mean of $\mu$ and a variance of $\sigma^{2}$, the truncated normal distribution can be used to calculate expected loan loss and the variance of that loss.

Let $\mathrm{P}$ be the required loan payment so that the loss is:

$$
\begin{aligned}
& L=P-x \text { if } x<P \\
& L=0 \text { if } \geq P .
\end{aligned}
$$

The probability density function and cumulative density function of $x$ is denoted by $f[x]$ and $F[x]$, respectively.

\section{Expected Loss Proof:}

$$
\begin{aligned}
E L & =\int_{-\infty}^{\infty} L f[x] d x \\
& =\int_{P}^{\infty} 0 f[x] d x+\int_{-\infty}^{P}(P-x) f[x] d x \\
& =P(F[P])-\int_{-\infty}^{P} x f[x] d x .
\end{aligned}
$$

Then,

$$
\begin{aligned}
E L & =P(F[P])-\int_{-\infty}^{P}\left(\mu f[x]-\sigma^{2} f^{\prime}[x]\right) d x \text { follows from Note } 1 \text { below, and } \\
& =P(F[P])-\mu F[P]+\sigma^{2} f[P] \\
& =(P-\mu) F[P]+\sigma^{2} f[P] .
\end{aligned}
$$

Note 1:

Let $x \sim N\left(\mu, \sigma^{2}\right)$ with pdf $f[x]$ and $\operatorname{cdf} F[x]$.

Then, 


$$
f^{\prime}[x]=-\left(\frac{x-\mu}{\sigma^{2}}\right) f[x] .
$$

Therefore,

$$
\sigma^{2} f^{\prime}[x]=(\mu-x) f[x]
$$

and

$$
x f[x]=\mu f[x]-\sigma^{2} f^{\prime}[x] .
$$

Variance of Loss Proof:

$$
\begin{aligned}
V L & =\int_{-\infty}^{\infty}(L-E L)^{2} f[x] d x \\
& =\int_{P}^{\infty}(-E L)^{2} f[x] d x+\int_{-\infty}^{P}(L-E L)^{2} f[x] d x \\
& =E L^{2}(1-F[P])+\int_{-\infty}^{P}\left(L^{2}-2 L(E L)+E L^{2}\right) f[x] d x \\
& =E L^{2}(1-F[P])+\int_{-\infty}^{P} L^{2} f[x] d x-2 E L \int_{-\infty}^{P} L f[x] d x+E L^{2} F[P] \\
& =E L^{2}(1-F[P])+\int_{-\infty}^{P}(P-x)^{2} f[x] d x-2 E L^{2}+E L^{2} F[P] \\
& =\int_{-\infty}^{P}\left(P^{2}-2 P x+x^{2}\right) f[x] d x-E L^{2} \\
& =P^{2} F[P]-2 P \int_{-\infty}^{P} x f[x] d x+2 P \int_{-\infty}^{P} x^{2} f[x] d x-E L^{2} .
\end{aligned}
$$

Then,

$$
\begin{aligned}
V L= & P^{2} F[P]-2 P \int_{-\infty}^{P}\left(\mu f[x]-\sigma^{2} f^{\prime}[x]\right) d x \\
& +\int_{-\infty}^{P}\left(4 f^{\prime \prime}[x]+\left(\sigma^{2}+\mu^{2}\right) f[x]-2 \mu \sigma^{2} f^{\prime}[x]\right) d x-E L^{2}
\end{aligned}
$$

is obtained by substituting from Note 1 above and Note 2 below. Therefore,

$$
\begin{aligned}
V L= & P^{2} F[P]-2 P \mu F[P]+2 P \sigma^{2} f[P]+\sigma^{4} f^{\prime}[P]+\left(\sigma^{2}+\mu^{2}\right) F[P] \\
& -2 \mu \sigma^{2} f[P]-E L^{2}
\end{aligned}
$$




$$
\begin{aligned}
& =\left(P^{2}-2 P \mu+\sigma^{2}+\mu^{2}\right) F[P]+\left(2 P \sigma^{2}-2 \mu \sigma^{2}\right) f[P]+\sigma^{4}\left(\frac{\mu-P}{\sigma^{2}}\right) f[P]-E L^{2} \\
& =\left((P-\mu)^{2}+\sigma^{2}\right) F[P]+\sigma^{2}(P-\mu) f[P]-E L^{2} \\
& =(P-\mu) F[P](P-\mu)+\sigma^{2} F[P]+\sigma^{2}(P-\mu) f[P]-E L^{2} \\
& =\left(E L-\sigma^{2} f[P]\right)(P-\mu)+\sigma^{2} F[P]+\sigma^{2}(P-\mu) f[P]-E L^{2} \\
& =\sigma^{2} F[P]+(P-\mu) E L-E L^{2} .
\end{aligned}
$$

Note 2:

Let $x \sim N\left(\mu, \sigma^{2}\right)$ with pdf $f[x]$ and $\operatorname{cdf} F[x]$. Then,

$$
f^{\prime}[x]=-\left(\frac{x-\mu}{\sigma^{2}}\right) f[x]
$$

and

$$
f^{\prime \prime}[x]=-\frac{f[x]}{\sigma^{2}}+\frac{\mu-x}{\sigma^{2}} f^{\prime}[x] .
$$

Therefore,

$$
\begin{aligned}
f^{\prime \prime}[x]= & -\frac{f[x]}{\sigma^{2}}+\left(\frac{\mu-x}{\sigma^{2}}\right)^{2} f[x] \\
\sigma^{4} f^{\prime \prime}[x] & =-\sigma^{2} f[x]+(\mu-x)^{2} f[x] \\
& =-\sigma^{2} f[x]+\mu^{2} f[x]-2 \mu x f[x]+x^{2} f[x] .
\end{aligned}
$$

Using the results from Note 1 , and substituting for $x f[x]$ yields:

$$
\begin{aligned}
x^{2} f[x] & =\sigma^{4} f^{\prime \prime}[x]+\sigma^{2} f[x]+\mu^{2} f[x]-2 \mu \sigma^{2} f^{\prime}[x] \\
& =\sigma^{4} f^{\prime \prime}[x]+\left(\sigma^{2}+\mu^{2}\right) f[x]-2 \mu \sigma^{2} f^{\prime}[x] .
\end{aligned}
$$




\section{Appendix B}

\section{Calculating the Expected Loss and Variance of Losses in a Portfolio}

Consider a portfolio with two sectors with each loan in each sector having identical means and variances. If $w_{i}$ is the proportion of sector $i$ in the entire portfolio, then the expected loss for the entire portfolio is:

$$
E L_{P}=w_{1} E L_{1}+w_{2} E L_{2} .
$$

The correlation between loans within a sector is given by $\rho_{i}$, such that the variance of losses by sector is:

$$
\begin{aligned}
& \rho_{1} V L_{1}=\text { the variance of losses in the first portfolio } \\
& \rho_{2} V L_{2}=\text { the variance of losses in the second portfolio. }
\end{aligned}
$$

The correlation between the two sectors is designated as $R$, such that the portfolio variance of losses is:

$$
V L_{P}=w_{1}^{2} \rho_{1} V L_{1}+w_{2}^{2} \rho_{2} V L_{2}+2 \mathrm{R} w_{1} w_{2} \sqrt{\rho_{1}} \sqrt{\rho_{2}} \sqrt{V L_{1}} \sqrt{V L_{2}} .
$$

If $\rho_{1}=\rho_{2}=\rho$ and $V L_{1}=V L_{2}=V L$, then

$$
V L_{P}=\left(w_{1}^{2}+w_{2}^{2}\right) \rho V L+2 \mathrm{R} w_{1} w_{2} \rho V L,
$$

As the number of sectors approaches infinity, with each sector having equal weight in the portfolio, then

$$
V L_{P}=\mathrm{R} \rho V L .
$$




\section{Appendix C}

\section{Beta Distribution of Losses}

The Beta distribution provides a reasonable approximation for calculating loss distributions when the number of loans exceeds 10 . The parameters of the $\operatorname{Beta}(\alpha, \beta)$ distribution are defined by expected loan losses $(E L)$ and the variance of loan losses $(V L)$ where $\alpha$ and $\beta$ are given by:

$$
\alpha=E L_{n}\left[\frac{E L_{n}\left(1-E L_{n}\right)}{V L_{n}}-1\right]
$$

and

$$
\beta=\left(1-E L_{n}\right)\left[\frac{\left(E L_{n}\left(1-E L_{n}\right)\right)}{V L_{n}}-1\right]
$$

The Beta distribution of loan losses provides the probability of loan losses being less than a prescribed level. The inverse Beta distribution provides the critical loan loss level for that prescribed probability. If the prescribed probability is set at 0.996 , then the critical loss associated will only be exceeded with a probability of $(1 / 250)=0.004$. The probability of 0.996 is usually used in VaR analyses. The critical loan loss level is the amount of capital required to offset loan risk.

It is necessary to adjust the required capital reserves calculated using the Beta distribution because, at low loan numbers, the Beta distribution underestimates capital reserve requirements. However, as the number of loans increase, the Beta distribution is relatively accurate. For a single loan, the exact capital requirement can be calculated because the underlying funds available to service the loan are normally distributed. The difference between the exact capital requirements and that estimated using the Beta distribution in the single loan case is designated as $d$. For loan numbers greater than $1, d_{n}=(d) 0.65^{n-1}$ where $n$ is the number of loans being simulated. The term $d_{n}$ represents the additional capital reserve requirements beyond that 
estimated using the Beta distribution. Note that $d_{n}$ quickly approaches 0 as $n$ becomes large. The scalar 0.65 is based upon simulations using small numbers of loans.

It is worth noting that a closed-form mathematical relation does not exist (although simulations results can be produced) for calculating capital reserve requirements when more than one loan is being considered. However, the simulation is very cumbersome, and the relatively simpler Beta distribution approach is relatively accurate if adjustments are made when loan numbers are small. 


\section{Appendix D}

\section{Estimating Farm-level Revenue Correlations from County-Level Data}

The VaR model presented in the narrative requires an estimate of farm-level revenue correlations across sectors. Because farm-level time series data are not usually available, we develop a method to for estimating the desired correlation using available county-level data. For simplicity, we initially assume that two farms each grow a single, but different, crop and that county level price and crop yields are available. We develop the procedure for estimating revenue correlations for a wheat farm and a corn farm.

Consider the following notation:

Wheat: $\quad W=$ Wheat Price

$Y=$ County Wheat Yield

$y=$ Wheat Farm Yield $-Y$ (Deviation of farm yield from County Yield)

$R_{i}=$ wheat farm revenue $=W(Y+y)$

$\sigma_{i}=$ standard deviation of wheat farm revenue

Corn: $\quad B=$ Corn Price

$V=$ County Corn Yield

$V=$ Corn Farm Yield $-V$ (Deviation of farm yield from County Yield)

$R_{j}=$ corn farm revenue $=B(V+v)$

$\sigma_{j}=$ standard deviation of corn farm revenue

$\sigma_{i, j}=$ covariance between wheat farm and corn farm revenues

$\rho=$ correlation between wheat farm and corn farm revenues 
(D.1) $\rho=\frac{\sigma_{i, j}}{\sigma_{i} \sigma_{j}}$

An estimate for the first term in the denominator (squared) of (D.1) is given by

(D.2) $\sigma_{i}^{2}=E\left[\left(R_{i}-E\left[R_{i}\right]\right)^{2}\right]$

(D.3) $=E\left[R_{i}^{2}\right]-E\left[R_{i}\right]^{2}$

$$
=E\left[(W(Y+y))^{2}\right]-(E[W(Y+y)])^{2}
$$

$$
=E\left[W^{2}(Y+y)^{2}\right]-(E[W Y]+E[W y])^{2}
$$

$$
=E\left[W^{2}\left(Y^{2}+2 Y y+W^{2}+y^{2}\right)\right]-(E[W] E[Y]+E[W] E[y])^{2}
$$

$$
=E\left[W^{2}\right] E\left[Y^{2}\right]+2 E\left[W^{2}\right] E[Y] E[y]+E\left[W^{2}\right]\left[E y^{2}\right]-(E[W] E[Y]+E[W] E[y])^{2}
$$

Given that $E[y]=0$ and that prices and yields are assumed to be independent at the farm and county levels,

$$
=E\left[W^{2}\right]\left(E\left[Y^{2}\right]+E\left[y^{2}\right]\right)-E[W]^{2} E[Y]^{2}
$$

From the formula for variance, we obtain $E\left[Y^{2}\right]=\sigma_{Y}^{2}+E[Y]^{2}$ and $E\left[W^{2}\right]=\sigma_{W}^{2}+E[W]^{2}$. Upon substitution into equation (D.8), we obtain

$$
=\left(\sigma_{W}^{2}+E[W]^{2}\right)\left(\sigma_{Y}^{2}+E[Y]^{2}+\sigma_{y}^{2}+E[y]^{2}\right)-E[W]^{2} E[Y]^{2}
$$

Since $E[y]=0$

$$
=\left(\sigma_{W}^{2}+E[W]^{2}\right)\left(\sigma_{Y}^{2}+E[Y]^{2}+\sigma_{y}^{2}\right)-E[W]^{2} E[Y]^{2}
$$

Likewise, the second term in the denominator (squared) of (D.1) is given by:

(D.11) $\sigma_{j}^{2}=\left(\sigma_{B}^{2}+E[B]^{2}\right)\left(\sigma_{V}^{2}+E[V]^{2}+\sigma_{v}^{2}\right)-E[B]^{2} E[V]^{2}$

The numerator of (D.1) is the covariance between the two revenue streams and is is given by:

(D.12) $\sigma_{i, j}=E\left[\left(R_{i}-E\left[R_{i}\right]\right)\left(R_{j}-E\left[R_{j}\right]\right)\right]$

(D.13) $=E\left[R_{i} R_{j}-R_{i} E\left[R_{j}\right]-R_{j} E\left[R_{i}\right]+E\left[R_{i}\right] E\left[R_{j}\right]\right]$

(D.14) $=E\left[R_{i} R_{j}\right]-E\left[R_{i}\right] E\left[R_{j}\right]$ 
(D.15) $E\left[R_{i} R_{j}\right]=E[W(Y+y) B(V+v)]$

Assuming farm and county prices and yields are independent,

$$
=E[W B](E[Y V]+E[Y v]+E[V y]+E[v y])
$$

To further reduce the expression, we first show that $E[Y v]=0$.

(D.17) $E[Y v]=\frac{\sum_{k} Y v_{k}}{n}$ where $v_{k}$ is the kth corn farm yield deviation.

Since $Y$ is constant across all farms in a given year, the numerator in (D.17) can be written as $Y \sum_{k} v_{k}=0$. Hence, $E[Y v]=0$.

By analogy, $E[V y]=0$.

Further simplification is provided by proving that $E[v y]=0$.

Allow the number of wheat farms in a county to be $n$, and the number of corn farms in a county to be $m$. Then

(D.18) $E[v y]=\frac{\sum_{k} \sum_{u} v_{k} y_{u}}{n * m}$

$$
=\frac{\sum_{k}\left(v_{k} \sum_{u} y_{u}\right)}{n * m}
$$

Since $\sum_{u} y_{u}=0$, then, $E[v y]=0$.

Hence, equation (D.16) becomes

(D.20) $E\left[R_{i} R_{j}\right]=E[W B](E[Y V]$

Substituting (D.20) into (D.14) yields

(D.21) $\sigma_{i, j}=E[W B] E[Y V]-E\left[R_{i}\right] E\left[R_{j}\right]$

Recall that $E[Y V]=E[Y] E[V]+r_{Y, V} \sigma_{Y} \sigma_{V}$ and $E[W B]=E[W] E[B]+r_{W, B} \sigma_{W} \sigma_{B}$ where $r$ is the correlation coefficient between the subscripted variables. Then,

$$
\sigma_{i, j}=\left(E[W] E[B]+r_{W, B} \sigma_{W} \sigma_{B}\right)\left(E[Y] E[V]+r_{Y, V} \sigma_{Y} \sigma_{V}\right)-E[W] E[B] E[Y] E[V]
$$

and, 
(D.23) $\quad \rho=\frac{\left(E[W] E[B]+r_{W, B} \sigma_{W} \sigma_{B}\right)\left(E[Y] E[V]+r_{Y, V} \sigma_{Y} \sigma_{V}\right)-E[W] E[B] E[Y] E[V]}{\sqrt{\left(E[W]^{2}+\sigma_{W}^{2}\right)\left(E[Y]^{2}+\sigma_{Y}^{2}+\sigma_{y}^{2}\right)-E[W]^{2} E[Y]^{2}} \sqrt{\left(E[B]^{2}+\sigma_{B}^{2}\right)\left(E[V]^{2}+\sigma_{V}^{2}+\sigma_{v}^{2}\right)-E[B]^{2} E[V]^{2}}}$

Further simplification occurs by allowing $\psi$ to represent coefficients of variation, and dividing the numerator and denominator by $E[W] E[B] E[Y] E[V]$ which yields:

(D.24) $\rho=\frac{\left(1+r_{W, B} \psi_{W} \psi_{B}\right)\left(1+r_{Y, V} \psi_{Y} \psi_{V}\right)-1}{\sqrt{\left(1+\psi_{W}^{2}\right)\left(1+\psi_{Y}^{2}+\psi_{y}^{2}\right)-1} \sqrt{\left(1+\psi_{B}^{2}\right)\left(1+\psi_{V}^{2}+\psi_{v}^{2}\right)-1}}$

Equation (D.24) is used to provide an estimate of the correlation coefficient between wheat farms and corn farms using county level data. If one is interested in the correlation coefficient between two wheat farms in a county, then $\psi_{W}=\psi_{B}, \psi_{Y}=\psi_{V}, \psi_{y}=\psi_{v}$, and $r_{W, B}=r_{Y, V}=1$. In the case of estimating the revenue correlation coefficient between wheat and oil, the " $B$ " subscripts represent the relative correlation coefficients and coefficients of variation for the oil commodity. 